\title{
Corrigendum: Hydrodynamic Connectivity of Habitats of Deep-Water Corals in Corsair Canyon, Northwest Atlantic: A Case for Cross-Boundary Conservation
}

\author{
Anna Metaxas ${ }^{1 *}$, Myriam Lacharité $^{2}$ and Sarah N. de Mendonça ${ }^{1}$ \\ ${ }^{1}$ Department of Oceanography, Dalhousie University, Halifax, NS, Canada, ${ }^{2}$ Applied Research, Nova Scotia Community \\ College, Dartmouth, NS, Canada
}

Keywords: deep-water corals, connectivity, area-based conservation, cross-boundary collaboration, submarine canyons, hydrodynamics, continental slope, fishery closures

\section{A Corrigendum on}

OPEN ACCESS

Edited by:

J. Murray Roberts,

University of Edinburgh, United Kingdom

Reviewed by: Alan David Fox,

University of Edinburgh, United Kingdom

*Correspondence: Anna Metaxas metaxas@dal.ca

Specialty section:

This article was submitted to Deep-Sea Environments and Ecology, a section of the journal Frontiers in Marine Science

Received: 03 July 2019 Accepted: 22 August 2019 Published: 06 September 2019

Citation:

Metaxas A, Lacharité $M$ and de Mendonça SN (2019) Corrigendum: Hydrodynamic Connectivity of Habitats of Deep-Water Corals in Corsair Canyon, Northwest Atlantic: A Case for Cross-Boundary Conservation. Front. Mar. Sci. 6:554. doi: 10.3389/fmars.2019.00554
Hydrodynamic Connectivity of Habitats of Deep-Water Corals in Corsair Canyon, Northwest Atlantic: A Case for Cross-Boundary Conservation

by Metaxas, A., Lacharité, M., and de Mendonça, S. N. (2019). Front. Mar. Sci. 6:159. doi: 10.3389/fmars.2019.00159

In the original article, there were mistakes in Figures 8-11 and Table $\mathbf{4}$ as published. A mistake was made in the original tracking code during interpolation of the velocity fields from the ocean circulation model. Briefly, the fields were weighted by distance to the three nearest discrete points, rather than the inverse weight by distance to the same three nearest points (the proper approach). The outcome of this error is that velocities most resembled distant points rather than close ones. The corrected Figures 8-11 and Table $\mathbf{4}$ appear below.

In addition, in the original article, there was an error. To account for the above-stated mistake, a correction has been made to the Results, Hydrodynamic Connectivity, paragraphs 1-4:

"Seasonal and inter-annual patterns of occurrence of predicted track origins that ended near the mouth of Corsair Canyon were most persistent from immediately adjacent areas: Corsair Canyon proper, Georges Canyon, and Heezen Canyon (Figure 8 and Table 4). Occurrence in these areas among all assessed months and years was observed in 34.6, 65.8, and $29.0 \%$ of all predicted tracks, respectively. Estimated connectivity from sites in the Northeast Channel (northeast of Corsair Canyon) occurred in 18.4 and $11.2 \%$ of total tracks for the deep and shallow areas, respectively. When pooled, the Northeast Channel could thus be a potentially important source with a probability of occurrence of $\sim 30 \%$ within 60 days. Predicted connectivity from the deep area in Northeast Channel was clearly stronger in winter; for example 244 tracks occurred in January in 8 years, compared to 31 tracks in September in 6 years. Predicted connectivity from more distant canyons southwest of Corsair Canyon was more sporadic. Occurrence in these areas ranged from $5.3 \%$ of tracks with Lydonia Canyon to 9.6\% of tracks with Nygren Canyon in 4-10 years. Despite its distance from Corsair Canyon, occurrence in Oceanographer Canyon was predicted to occur in $5.9 \%$ of all tracks. Predicted connectivity with these canyons was most evident in May and September, with tracks occurring in September in 7-8 years."

"Mean residence time in each zone (calculated as the total time a track was located in that zone) was estimated at $16 \mathrm{~h}$ over all months and zones of interest (Figure 9). Short residence times 


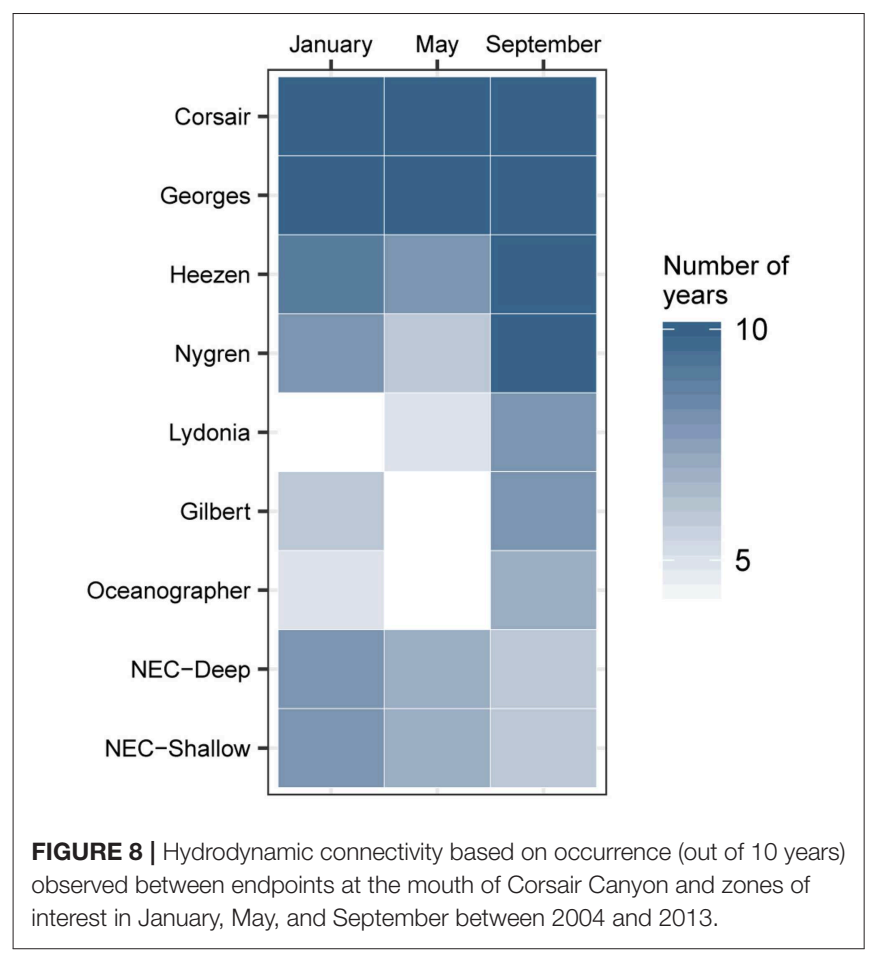

were observed in areas southwest of Corsair Canyon, in Georges Canyon and Heezen Canyon, and particularly in Nygren Canyon (mean: 5.4, 7.9, and $9.0 \mathrm{~h}$ in May, January, and September, respectively). In contrast, mean residence times were longer in Lydonia Canyon, Gilbert Canyon and Oceanographer Canyon in September (19.1, 14.8, and 20.7 h respectively). Mean residence time was estimated to be consistently above the grand mean in January in the deep area of Northeast Channel $(52.4 \mathrm{~h})$, and in the shallow area $(31.3 \mathrm{~h})$. We attribute this pattern to the effect of tides in Northeast Channel. The longest residence times ( $>200 \mathrm{~h}$ ) were observed in January in the deep area of Northeast Channel and Oceanographer Canyon (single occurrence of $237 \mathrm{~h}$ )."

"Mean minimum transit time between the mouth of Corsair Canyon and zones of interest was estimated at 15.1 days prior to track end time across all years and months (Figure 10). As expected, areas nearer the mouth of Corsair Canyon (Corsair Canyon proper and Georges Canyon) showed short mean transit time, particularly in January for Corsair Canyon proper (1.8 days) and in May for Georges Canyon (0.9 days). Minimum transit time increased with increasing southwestward distance from Corsair Canyon at Heezen Canyon (3.7-8.0 days), Nygren Canyon (15.6-19.2), and Oceanographer Canyon (20.4-25.7). Estimated minimum transit times from Northeast Channel varied between 10.2 and 38.4 days and were generally faster for

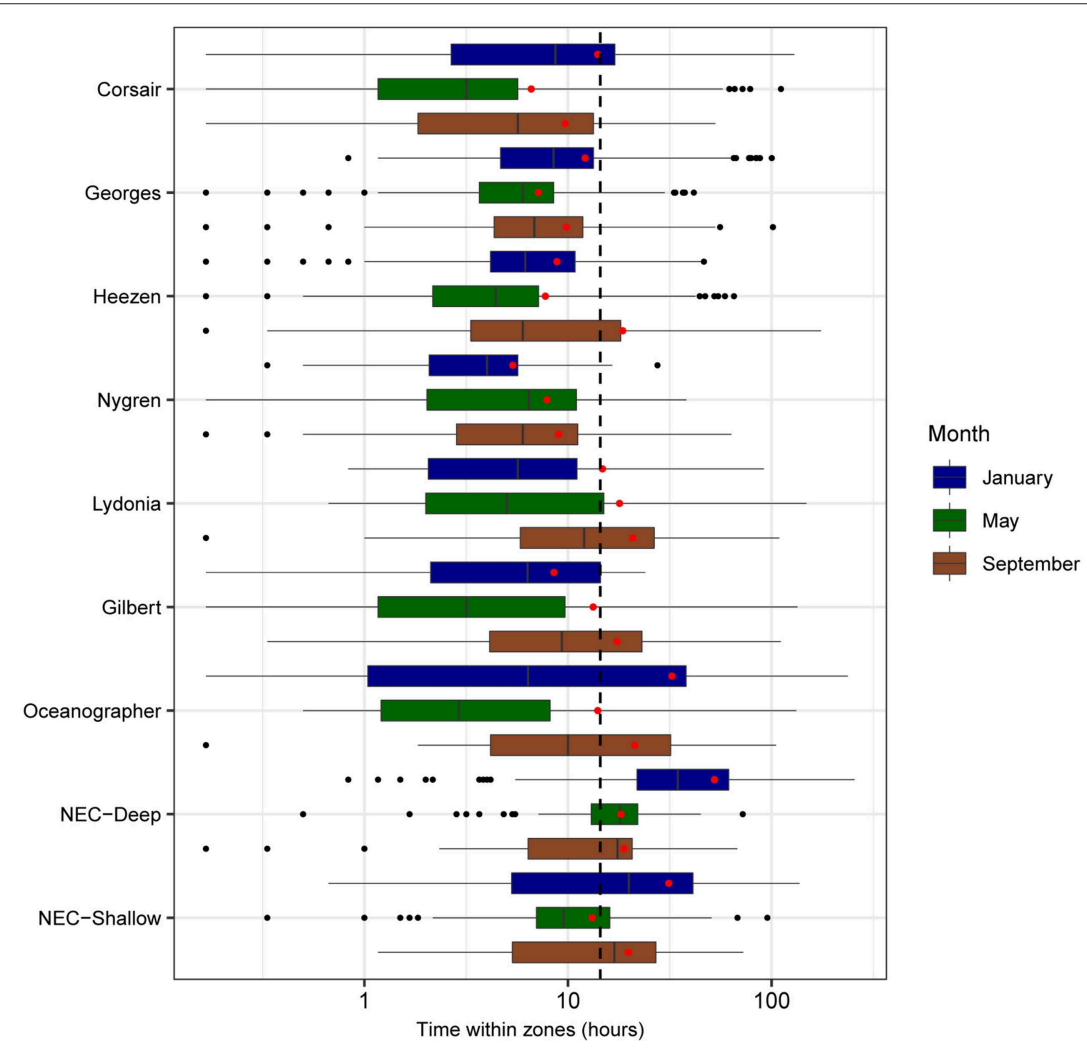

FIGURE 9 | Boxplots of residence time (h) for all tracks overlapping zones of interest segregated by month (sample sizes for the zone-month combinations are given in Table 4). Mean residence times for each month-zone combination are shown (red diamonds), as well as overall average (black dashed line). 


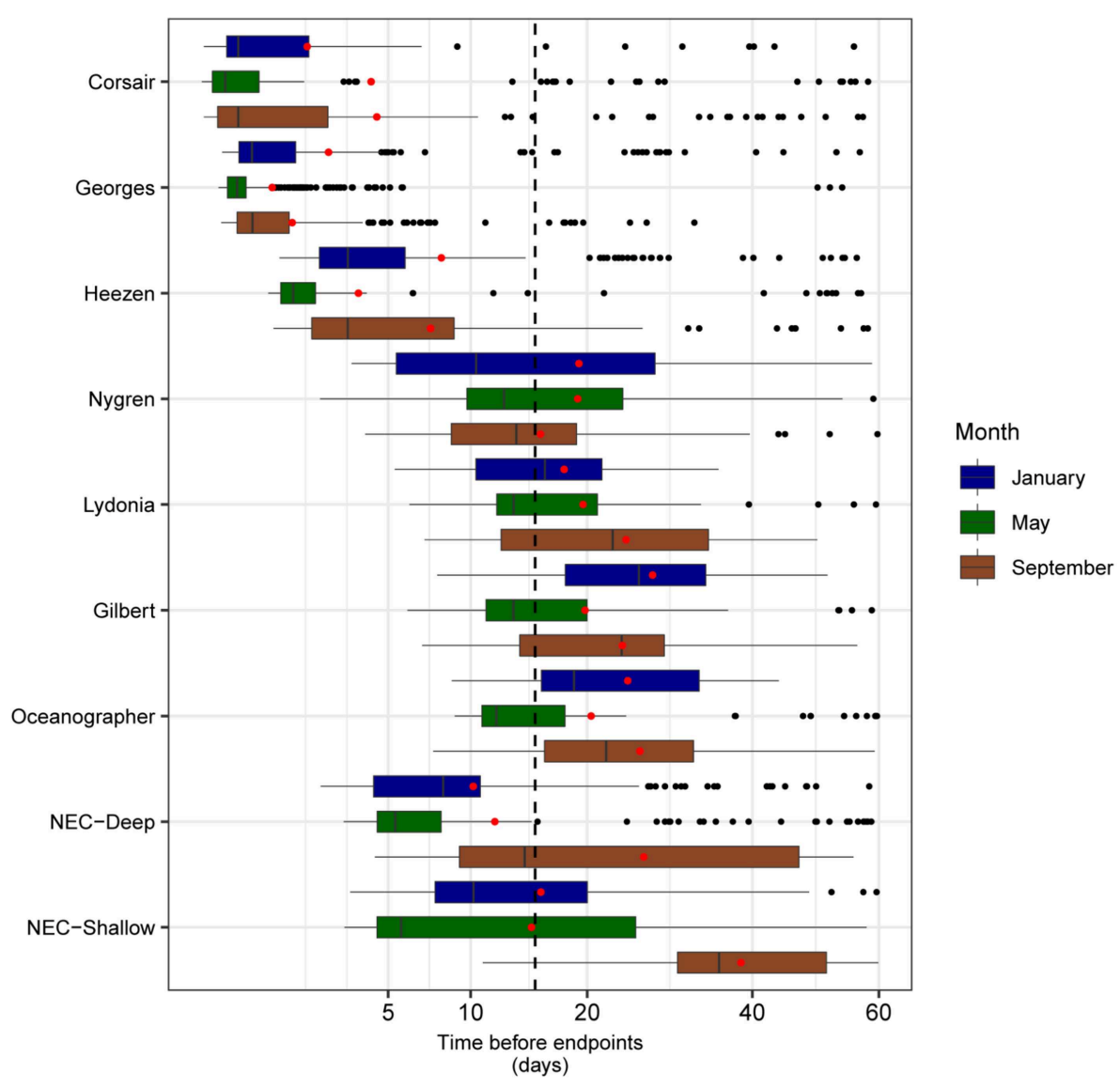

FIGURE 10 | Boxplots of mean minimum transit time calculated from all tracks overlapping each zone of interest, segregated by month (sample sizes for the zone-month combinations are given in Table 4). Mean transit times for each month-zone combination (red diamonds) and overall average (black dashed line) are also shown.

the deep than shallow area. Similar patterns were predicted for the maximum transit time from the zones of interest (data not shown). Maximum transit times reached $\sim 30$ days in Gilbert and Oceanographer Canyons and 41 days in the shallow area of Northeast Channel."

"The estimated position of tracks varied among months during the surveyed period (Figure 11). In January, most tracks straddled the upper continental slope at depths $<2000 \mathrm{~m}$. To the southwest, the tracks extended at the farthest to Nygren Canyon, then diverting offshore into deeper waters. To the northeast, tracks were predicted to occur along the slope at the mouth of Northeast Channel, but rarely found northeastward of the Channel. In May, tracks originating from the northeast along the slope close to the shelf break appeared restricted by the $1000-\mathrm{m}$ isobath. Estimated tracks reached further south than in January, most immediately offshore of Oceanographer Canyon, Gilbert Canyon and Lydonia Canyon, without penetrating into the canyons. Around the middle of Georges Bank, tracks extend further offshore down to the 3000$\mathrm{m}$ isobath. In September, consistent with previous observations, no connectivity was predicted with areas northeast of Corsair Canyon. Most tracks originated from the southwest of Corsair
Canyon, beyond Oceanographer Canyon. Most of these tracks, however, were confined to the 3000-m isobath, in the upper slope area extending immediately north of Corsair Canyon to Oceanographer Canyon. Overall, high interannual variability in spatial patterns was detected. The areas where $>50 \%$ of tracks were predicted to occur were restricted to the immediate adjacent region surrounding Corsair Canyon."

Furthermore, a correction has also been made to the Discussion, paragraph two:

"Although the populations are protected, their viability and ability to recover from previous damage by human activity is not necessarily ensured. For spatially fragmented populations, population persistence (or recovery from fishing) depends in part on recruitment and colonization. Recruitment to a population can be either through self-seeding, or through dispersal from an allochthonous source and adequate connectivity with the source population. For coral populations in Corsair Canyon, allochthonous supply, as predicted solely by hydrodynamic connectivity, that originated from Georges and Heezen Canyons to the southwest of Corsair Canyon, was the most consistent during all seasons and most years. Of these, only Georges Canyon is within Canada's EEZ and based on our data has 

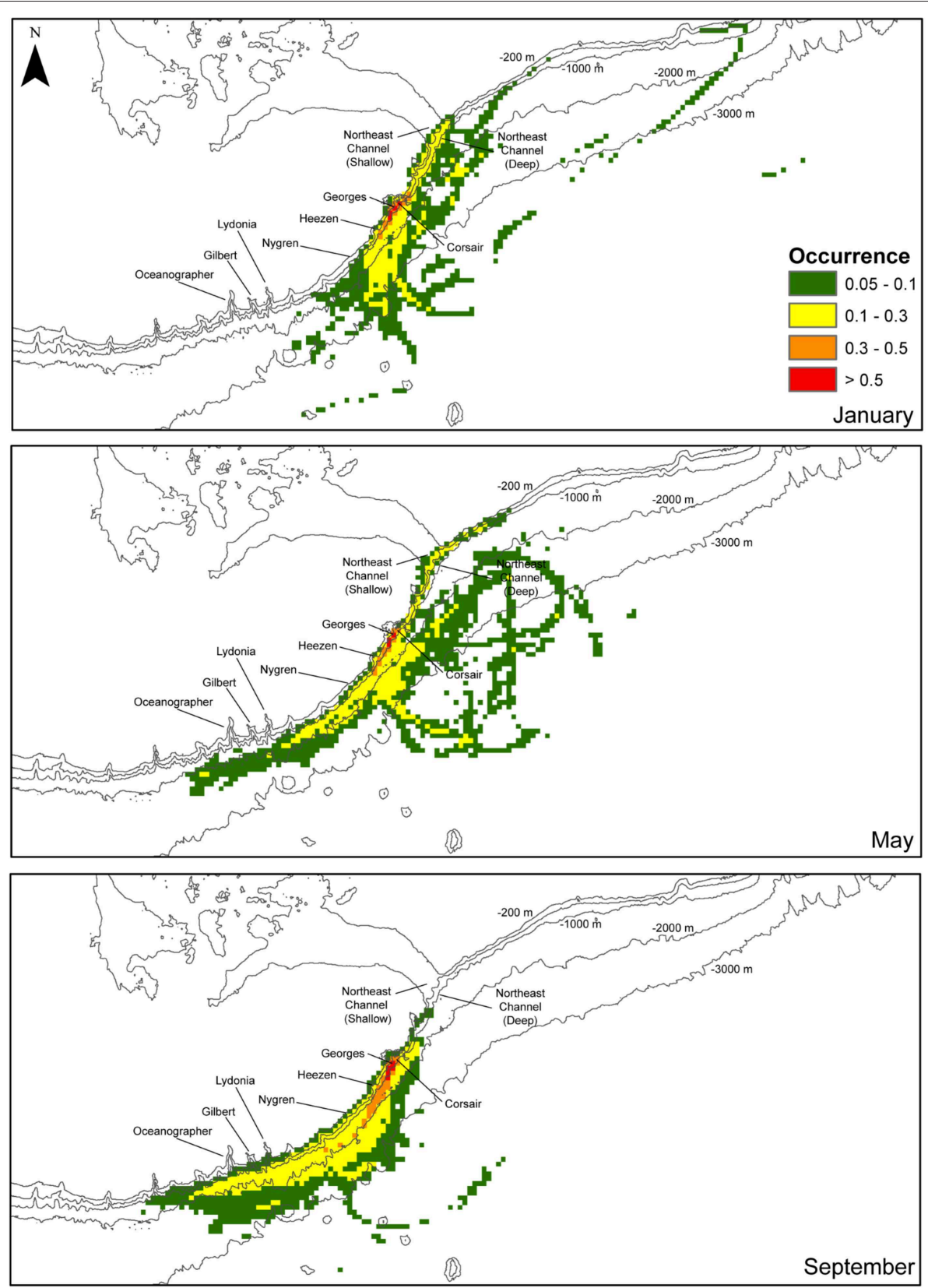

FIGURE 11 | Fraction of the total number of tracks (0-1) of all tracks in the region surrounding the mouth of Corsair Canyon over the maximum temporal length of release (60 d) segregated by month: January, May, and September (total of 750 tracks for each month). Densities were computed on a $5 \mathrm{~km} \times 5 \mathrm{~km}$ grid. Fractions below 0.05 are not shown.

very sparse populations of corals that can supply recruits. The NECCCA, the only location with significant coral aggregations of $P$. arborea on the continental shelf break and slope within the Canadian EEZ, exhibited some predicted hydrodynamic connectivity with Corsair Canyon, particularly in winter and spring. Thus, NECCCA may be a source of recruits if winter and spring encompass the spawning season of $P$. arborea, which is currently unknown. However, based on our results in winter, downwelling and seaward offshore advection through Corsair
Canyon may also be more frequent, arguably preventing flow into it and limiting its hydrodynamic connection with NECCCA. Our results suggest that Heezen Canyon, and to a lesser extent Nygren Canyon, which harbor high densities of $P$. arborea (Metaxas, personal observation), likely are the most consistent larval sources for the populations in Corsair Canyon. Predicted tracks ending in Corsair Canyon originate from regions in close proximity on the continental slope within 1-2 days, but more broadly over the shelf over periods of 30-35 days. These results 
TABLE 4 | Number of tracks originating from each of the 9 zones of interest and ending at 15 endpoints offshore of Corsair Canyon (northwest Atlantic).

\begin{tabular}{lcccc}
\hline Zone of interest & January & May & September & Total \\
\hline Corsair Canyon & 389 & 185 & 205 & 779 \\
Georges Canyon & 462 & 469 & 549 & 1480 \\
Heezen Canyon & 193 & 250 & 210 & 653 \\
Nygren Canyon & 35 & 52 & 129 & 216 \\
Lydonia Canyon & 15 & 37 & 67 & 119 \\
Gillbert Canyon & 22 & 41 & 76 & 139 \\
Oceanographer Canyon & 26 & 50 & 56 & 132 \\
NEC-Deep & 244 & 138 & 31 & 413 \\
NEC-Shallow & 94 & 132 & 26 & 252 \\
\hline
\end{tabular}

For each endpoint, tracks terminated on 5 days (11th - 15th) in January, May, and September from 2004-2013 at 12:00pm UTC ( $=$ max. 750 tracks per month). 'NEC,' Northeast Channel.

suggest that the geographic range of potential larval sources will depend on larval duration, although likely restricted to the continental shelf and slope (and even the Gulf of Maine) because deep water corals are not found on the sedimentary habitats beyond the continental slope."

Lastly, a correction has been made to the Discussion, paragraph 4:

"Population persistence of the coral aggregations in Corsair Canyon may require the preservation of coral aggregations in Heezen and Nygren Canyons, i.e., within the EEZ of USA, as the most consistently emerging larval sources. The Northeast Canyons and Seamounts Marine National Monument, established in the USA in 2016, protects some canyons further south that do serve as minor source populations (particularly Oceanographer Canyon in autumn), but the boundary of the Monument does not extend as far north as Heezen and

\section{REFERENCES}

Aburto-Oropeza, O., Johnson, A. F., Agha, M., Allen, E. B., Allen, M. F., González, J. A., et al. (2018). Harnessing cross-border resources to confront climate change. Environ. Sci. Policy 7, 128-132. doi: 10.1016/j.envsci.2018. 01.001

Arafeh-Dalmau, N., Torres-Moye, G., Seingier, G., Montaño-Moctezuma, G., and Micheli, F. (2017). Marine spatial planning in a transboundary context: linking Baja California with California's network of marine protected areas. Front. Mar. Sci. 4:150. doi: 10.3389/fmars.2017.0 0150

Katsanevakis, S., Levin, N., Coll, M., Giakoumi, S., Shkedi, D., Mackelworth, P., et al. (2015). Marine conservation challenges in an era of economic crisis and
Nygren Canyons. In turn, given that Corsair Canyon may serve as a significant larval source to the southeast, its protection augments the probability of larval supply to canyons in the US EEZ. The broad geographic range over which tracks were predicted to occur over periods of 60 days indicate potential connectivity (however, of unknown magnitude) across the entire continental slope in the region and possibly the Gulf of Maine. Our results strongly suggest that crossboundary coordination is essential in the conservation of aggregations of deep-water corals in the northwest Atlantic, for ensuring larval exchange and connectivity. The importance in transboundary considerations and cooperation in spatial planning and conservation is being advocated particularly for the marine realm, where few physical barriers to the movement of individuals and populations exist (Arafeh-Dalmau et al., 2017; Aburto-Oropeza et al., 2018). For example, Arafeh-Dalmau et al. (2017) illustrated the feasibility of a transboundary networks of MPAs in the Ensenadian ecoregion, linking the more poorly sampled marine habitats of Baja California, Mexico with the well-established network of marine reserves in California USA. It is recognized that transnational efforts in marine conservation planning entail decisions complicated by multiple stakeholders, conservation targets and political climates. Including costs of conservation can facilitate the process as illustrated by a study on the crowded Mediterranean Sea (Mazor et al., 2014). Approaches, such as developing access to homogeneous data, promoting transboundary collaborations, developing joint management units, and improving monitoring and surveillance, have been proposed to overcome some of the considerable challenges in cross-boundary conservation (Katsanevakis et al., 2015).”

The authors apologize for these errors and state that they do not change the scientific conclusions of the article in any way. The original article has been updated. geopolitical instability: the case of the Mediterranean Sea. Mar. Policy 51, 31-39. doi: 10.1016/j.marpol.2014.07.013

Mazor, T., Giakoumi, S., Kirk, S., and Possingham, H. (2014). Large-scale conservation planning in a multinational marine environment: cost matters. Ecol. Appl. 24, 1115-1130. doi: 10.1890/13-1249.1

Copyright (c) 2019 Metaxas, Lacharité and de Mendonça. This is an open-access article distributed under the terms of the Creative Commons Attribution License (CC BY). The use, distribution or reproduction in other forums is permitted, provided the original author(s) and the copyright owner(s) are credited and that the original publication in this journal is cited, in accordance with accepted academic practice. No use, distribution or reproduction is permitted which does not comply with these terms. 